\title{
El procedimiento de solución de controversias de la OMC. La experiencia de América Latina y el Caribe
}

\author{
Gonzalo Biggs
}

1

ste artículo analiza la trascendencia para la región latinoamericana del procedimiento de solución de controversias que, en 1994, aprobara el Acuerdo de Marrakech por el que se establece la Organización Mundial de Comercio (omc). Su trascendencia proviene del aumento del volumen del comercio internacional de la región y el incremento consiguiente de las controversias comerciales en que participa. El procedimiento se aplica a las controversias entre algunos de los 148 países miembros respecto de las materias que abarca dicho Acuerdo y los 29 acuerdos multilaterales conexos que son su parte integrante. Destaca sus diferencias con las anteriores normas del GaTT y los demás procedimientos de solución de controversias internacionales. Describe los acuerdos que han generado el mayor número de controversias —antidumping, de subvenciones y medidas compensatorias, y de salvaguardias-, comenta la política de Estados Unidos y detalla las controversias en que han participado los países latinoamericanos, con especial referencia a la experiencia de Brasil.

• gbiggs@fivalabogados.cl 


\section{I}

\section{Introducción}

De todos los organismos internacionales existentes, el más importante para América Latina, en nuestra opinión, es la omc. Según un autor, sería el organismo internacional de mayor gravitación económica en el mundo. ${ }^{1}$

Su importancia está asociada a las reformas macroeconómicas y de apertura comercial del decenio de 1980, que convirtieron al comercio internacional en el motor principal del desarrollo económico de la región latinoamericana, y cuyo volumen prácticamente se triplicó en diez años. ${ }^{2}$ En efecto, en 1994 las exportaciones e importaciones de la región sumaban 323.000 millones de dólares y, en 2004, se elevaron a 860.000 millones. Paralelamente, el aumento del volumen del comercio mundial en el mismo período estuvo acom- pañado, como es lógico, del aumento consiguiente de las controversias o diferencias comerciales internacionales. Estos distintos factores explican la importancia crítica para los países de la región del procedimiento que administra el Órgano de Solución de Diferencias (OSD) de la omc. ${ }^{3}$

Este artículo analiza la trascendencia para la región latinoamericana del mencionado procedimiento o Entendimiento sobre solución de diferencias en la OMC (al que en adelante llamaremos Entendimiento) y que abarca los temas siguientes: evolución histórica e institucionalidad; innovaciones y comparación con otros procedimientos; política de Estados Unidos; controversias más frecuentes; experiencia de los países latinoamericanos y del Caribe; experiencia de Brasil, y conclusiones.

\section{II}

\section{Evolución histórica e institucionalidad de la omc}

\section{Antecedentes}

En 1946 la Conferencia de Bretton Woods dio nacimiento al Banco Mundial, al Fondo Monetario Internacional (FMI) y a la Organización Internacional del Comercio o, según su sigla en inglés, Iтo (International Trade Organization). Esta trilogía de instituciones tuvo por objeto promover las inversiones para el desarrollo y regular las balanzas de pagos y el comercio internacional, respectivamente. La creación de la гто fue negociada por las Naciones Unidas y culminó en la Car-

El autor ha sido incluido a propuesta del Gobierno de Chile en la lista indicativa de expertos no gubernamentales de la omc. Fue panelista en el reclamo de Canadá contra Estados Unidos por los derechos compensatorios provisionales aplicados a las importaciones de madera blanda, y en el reclamo de Brasil y otros países contra las Comunidades Europeas por sus subsidios al azúcar.

${ }^{1}$ Véase The World Trade Organization. Constitution and Jurisprudence (Jackson, 1999, p.101).

${ }^{2}$ El comercio exterior representó en 2004 el 44\% del PIB de la región (CEPAL, 2004, p. 8, y CEPAL, 1994, p. 39). ta de La Habana de 1948. Paralelamente, la liberación de los aranceles comerciales fue regulada por el Acuerdo General sobre Aranceles Aduaneros y Comercio de 1947, más conocido como GATT, cuya aplicación y supervisión fue asignada a la ITO. Sin embargo, el Congreso de los Estados Unidos rechazó establecer la Iто, con lo cual quedó vigente el GATT pero sin esa institucionalidad. Esa vigencia, además, fue solo provisional por cuanto el Acuerdo nunca obtuvo el número de ratificaciones exigido por su estatuto. ${ }^{4}$ Estos vacíos los llenaron la secretaría temporal que creara las $\mathrm{Na}$ ciones Unidas y que, con el tiempo, se convirtió en secretaría permanente, y el artículo XXV que estableció

\footnotetext{
${ }^{3}$ El osD fue establecido por el artículo 2 del Entendimiento que se aprobó en Marrakech junto con la creación de la omC.

${ }^{4}$ El artículo XXVI del GaTT exigió para la entrada en vigencia del Acuerdo la aceptación de los gobiernos enumerados en el Anexo $\mathrm{H}$ cuyos territorios representaran el $85 \%$ del comercio exterior total de los territorios de esos gobiernos. El plazo fijado por esta disposición expiró sin que se lograra esa aceptación. Véase Petersmann (1997, vol. II, p.46).
} 
un mecanismo de reuniones de las partes contratantes para asegurar la ejecución del Acuerdo, las que al actuar colectivamente se llamarían Partes Contratantes.

Además de exhibir esta débil institucionalidad, el GATT nació con dos grandes limitaciones. La primera fue la escasa presencia de países en desarrollo, ya que solo había siete de ellos entre los 23 miembros originales del GATT. De América Latina, los miembros originales y suscriptores del Acuerdo fueron Brasil, Chile y Cuba. ${ }^{5}$

La segunda limitación fue que su actividad estuvo limitada exclusivamente a la regulación de los aranceles aduaneros del comercio de bienes entre los países industrializados, sobre la base de los principios de trato nacional y de nación más favorecida. A pesar de estas limitaciones, el GATT logró subsistir y perdurar durante prácticamente 50 años. Además, a través de sus ocho rondas de negociaciones, pudo adoptar decisiones, resoluciones y protocolos que le permitieron evolucionar y ampliar su radio de acción, su representatividad y, muy gradualmente, sus responsabilidades hacia los países en desarrollo.

\section{Las controversias bajo el GATT}

Las controversias bajo el GATT en el período 1948-1994 del GATT se rigieron por sus artículos XXII y XXIII, los que, como se explica más adelante, permanecen vigentes. Estos artículos establecieron el derecho de los Miembros a formular, en los términos allí indicados, consultas o reclamos relativos a la aplicación del Acuerdo. Sin embargo, no establecieron un procedimiento para administrar las controversias; y entregaron a las Partes Contratantes - y no a órganos independientes - la autoridad para resolver esas controversias. Tampoco se contempló un procedimiento de apelación.

Durante las etapas iniciales, las disputas eran sometidas directamente a las Partes Contratantes; posteriormente, las resoluciones fueron entregadas a grupos de trabajo de hasta 20 delegados o representantes de los gobiernos -inclusive de las partes en disputacuyas recomendaciones se entregaban a las Partes Contratantes para su decisión final. En 1952 se establecieron paneles para resolver los reclamos fundados en el citado artículo XXIII y se acordó el principio según el cual se presume que una medida que infringe los acuerdos contraídos constituye un caso de nulidad

\footnotetext{
5 Véase el preámbulo del GATT de 1947, en Los resultados de la Ronda Uruguay de negociaciones comerciales multilaterales. Los textos jurídicos (GATT, 1994, p. 504). Las próximas citas al Acuerdo sobre la омс у a los acuerdos conexos, todos aprobados en Marrakech, se refieren a dicha publicación.
}

o menoscabo de los beneficios conferidos por las normas del GATT. En virtud de esta modificación, los miembros de los paneles ya no podían provenir de las partes en disputa, pero sus recomendaciones continuaban siendo entregadas a la decisión final de las Partes Contratantes. Las sucesivas resoluciones adoptadas a partir de 1952 suplieron la falta de un procedimiento definido y culminaron en 1989 con la aprobación de una nueva normativa, más elaborada y objetiva, que rigió hasta el término de la Ronda Uruguay. ${ }^{6}$

Sin embargo, el hecho de que las decisiones finales exigieran el consenso de todas las Partes Contratantes, inclusive de las partes en disputa, significó que, en definitiva, las controversias se resolvieran por la vía diplomática o política. Durante el período 1948-1994 se resolvieron 196 disputas, pero solo en un caso se autorizó la suspensión de concesiones por incumplimiento de las obligaciones de un Miembro bajo el Acuerdo. ${ }^{7}$

\section{Estructura institucional de la омс}

Antes de la actual y aún no concluida Ronda Doha, la Ronda Uruguay fue la última ronda de negociación del GATT y la primera en un país en desarrollo. Culminó con la reunión de Marrakech, de 15 de abril de 1994, y la aprobación por los 124 países participantes y las Comunidades Europeas ${ }^{8}$ del Acuerdo de Marrakech por el que se establece la creación de la OMC (al que en adelante llamaremos Acuerdo sobre la OMC), y de 29 acuerdos multilaterales conexos, 28 decisiones ministeriales y declaraciones, cuatro acuerdos plurilaterales ${ }^{9}$ y un entendimiento respecto de compromisos financieros.

Las negociaciones de la Ronda Uruguay se desarrollaron a nivel político y de ministerios de comercio. Sin embargo, la solución de las controversias generadas por la aplicación de los acuerdos respectivos han sido y son materias fundamentalmente jurídicas, como lo explicamos más adelante.

En contraste con la fragmentación que imperó bajo el GATT, en que no todas las partes ratificaron los mismos acuerdos (por ejemplo, dos tercios de los miembros no suscribieron los acuerdos de la Ronda

\footnotetext{
${ }^{6}$ Decisión de las Partes Contratantes del GATT, de 12 de abril de 1989, que aprobó normas y procedimientos para la solución de diferencias (OMC, 1995, p. 638).

7 Véase Petersmann (1997, vol. II, p. 46).

${ }^{8}$ En la nomenclatura de la omc se utiliza la denominación "Comunidades Europeas" para referirse a la Unión Europea, especialmente en relación con los procesos de solución de controversias. Por ese motivo en este artículo aparecen ambas denominaciones.

${ }^{9}$ Los cuatro acuerdos comerciales plurilaterales solo obligan a los países que los ratificaron.
} 
Tokyo de 1979), el Acuerdo sobre la OMC y los acuerdos conexos aprobados en Marrakech constituyen un acuerdo global integrado cuyos textos son igualmente obligatorios para la totalidad de los Miembros. ${ }^{10} \mathrm{La}$ normativa de la OMC se extiende no solo al comercio de bienes y servicios sino también a los subsidios, salvaguardias, medidas antidumping, normas de origen y demás materias comprendidas en los 29 acuerdos mencionados. La OMC es una organización con personalidad jurídica internacional - lo que no fue el caso del GATT - y tiene la responsabilidad de supervisar la aplicación del acuerdo principal y sus acuerdos conexos, incluido por cierto el Entendimiento. ${ }^{11}$

Los 148 países miembros siempre forman parte de los tres principales órganos de la oMc - la Conferencia Ministerial, el Consejo General y el Órgano de Solución de Diferencias (OSD) — y están representados en ellos. Esta original modalidad asegura el carácter multilateral y la representatividad de las decisiones de dichos órganos:

i) la Conferencia Ministerial está conformada por los representantes ministeriales de los Estados Miembros. Se reúne cada dos años y tiene autoridad para resolver todos los asuntos comprendidos en los acuerdos multilaterales adoptados en Marrakech;

ii) el Consejo General está conformado por los representantes acreditados en Ginebra de los gobiernos de los mismos Estados Miembros. En los intervalos entre las reuniones de la Conferencia Ministerial desempeña las funciones de esta. Se reúne con la frecuencia que considera procedente y administra y supervisa los distintos Consejos establecidos por el Acuerdo (comercio de servicios, mercancías y aspectos comerciales relacio- nados con la propiedad intelectual $)^{12}$ y desempeña además, cuando procede, las funciones de Órgano de Solución de Diferencias;

iii) el Órgano de Solución de Diferencias (OSD) está conformado por los mismos representantes del Consejo General. Administra las normas y procedimientos del Entendimiento y la solución de las diferencias que surjan de la aplicación de los acuerdos multilaterales abarcados. Sus funciones, como se ha dicho, son desempeñadas por el Consejo General. Se reúne mensualmente, puede tener su propio presidente y aprobar las normas que sean necesarias para el cumplimiento de sus funciones; ${ }^{13} \mathrm{y}$

iv) una Secretaría a cargo de un Director General que es designado por la Conferencia Ministerial y que, a su vez, designa al personal, se desempeña como jefe del personal y establece sus deberes y condiciones de servicio. Tanto el Director General como el personal de la Secretaría son funcionarios internacionales y no responden a las instrucciones de gobierno alguno. ${ }^{14}$

En las reuniones de la Conferencia Ministerial y del Consejo General, cada miembro tiene un voto. La práctica del GATT y de la OMC es que las decisiones se adoptan por consenso, el cual se produce cuando ningún Miembro presente en las reuniones en que estas se adoptan se opone formalmente a ellas. Así, una ausencia o abstención no impide el consenso. A falta de consenso y salvo disposición en contrario, las decisiones de la Conferencia Ministerial y del Consejo se adoptan por la mayoría de los votos emitidos. ${ }^{15} \mathrm{La}$ disposición en contrario, o excepción a esta regla, son las decisiones del OSD, que solo pueden adoptarse por consenso. ${ }^{16}$

\section{III}

\section{El procedimiento de la omc para}

\section{la solución de diferencias}

\begin{abstract}
Algunas innovaciones de la omc en el procedimiento de solución de diferencias, que lo distinguen de cualquier otro procedimiento internacional similar y que explican su eficiencia y eficacia, son entre otras las re-
\end{abstract}

${ }^{10}$ Artículo II (2) y (3) del Acuerdo sobre la OMC.

${ }^{11}$ Véase los artículos VIII y III del Acuerdo sobre la OMC. ferentes a la obligatoriedad y exclusividad de su jurisdicción, el carácter multilateral, la automaticidad, el

\footnotetext{
12 Véase el artículo IV(5) del Acuerdo sobre la omc.

${ }^{13}$ Véase el artículo IV(3) del Acuerdo sobre la oмc.

14 Véase el artículo VI del Acuerdo sobre la OMC.

15 Véase el artículo IX (I) del Acuerdo sobre la omc.

16 Véase el Artículo 2 (4) del Entendimiento.
} 
predominio de la ley en la resolución de las controversias, la preferencia por soluciones no contenciosas, el bajo costo, la rapidez y las modalidades de cumplimiento y ejecución de las resoluciones.

\section{Jurisdicción}

La jurisdicción de la omc es obligatoria, exclusiva, excluyente y multilateral.

Todo país Miembro que considera que otro Miembro ha infringido sus obligaciones bajo la OMC o sus acuerdos conexos, o que sus beneficios han sido menoscabados o anulados, tiene el derecho de iniciar -mediante las consultas correspondientes-el procedimiento de solución de diferencias. ${ }^{17}$ En ciertos casos, un Miembro con un interés comercial sustancial puede — con la aceptación del Miembro solicitante- asociarse a las consultas ${ }^{18}$ y procedimientos posteriores.

El Miembro emplazado, a su vez, está obligado a responder y no puede — como en otros organismoscuestionar con éxito esa jurisdicción, por cuanto esta ya fue aceptada cuando ratificó el Acuerdo sobre la OMC y los acuerdos multilaterales conexos. Esta particularidad debe contrastarse con los procedimientos de otros tribunales internacionales donde los cuestionamientos a la jurisdicción y otras incidencias son frecuentes y pueden retrasar u obstaculizar por años la resolución del fondo de una controversia.

La jurisdicción es también exclusiva y excluyente en el sentido de que cualquier infracción a los acuerdos de la omc solo puede ser juzgada o reparada conforme a sus normas y procedimientos. ${ }^{19}$ Un país Miembro no puede demandar a otro o pretender reparaciones por tales infracciones ante una jurisdicción o mediante procedimientos, nacionales o internacionales, distintos de aquellos establecidos por el sistema de la OMC y el Entendimiento.

El procedimiento es también multilateral en un doble sentido. En primer lugar, porque una vez infringido o cuestionado un acuerdo, el afectado no puede, legítimamente, responder con acciones unilaterales sin incurrir, a su vez, en una infracción. Su única acción posible debe canalizarse a través del procedimiento multilateral de la OMC. En segundo lugar, porque cada etapa del procedimiento debe ser aprobada por el OSD que está integrado por los representantes del conjunto

${ }^{17}$ Entendimiento, artículo 4 (4).

18 Entendimiento, artículo 4 (11).

19 Entendimiento, artículo 23 (1) y (2). de los Miembros de la omc. Así, por ejemplo, la iniciación de consultas, la formación y fallo de un panel, el fallo del Órgano Permanente de Apelación (en adelante Órgano de Apelación) o las resoluciones que aprueban la suspensión de concesiones u obligaciones, deben ser aprobadas por el OSD. Además, una vez iniciado el procedimiento, cualquier solución acordada mutuamente entre las partes debe ser concordante con la OMC y sus acuerdos conexos, y notificarse al OSD y Comités correspondientes. Esto último permite que otros Miembros puedan cuestionar las consecuencias que esa solución bilateral pueda tener sobre los acuerdos multilaterales respectivos. ${ }^{20}$

\section{Resolución de diferencias: predominio de la ley. Descripción de los órganos pertinentes}

Un cambio radical respecto del GATT ha sido el reemplazo de procedimientos en que prevalecían los acuerdos políticos y diplomáticos por uno en que las controversias son resueltas por tribunales independientes conforme a los hechos y la ley pertinente.

La ley aplicable es el conjunto de acuerdos conexos al Acuerdo sobre la omc y del cual son una parte integrante. El GATT de 1994 es uno de estos acuerdos conexos que, a su vez, incluye al GATT de 1947 y las decisiones, los procedimientos y la práctica consuetudinaria de sus Partes Contratantes. ${ }^{21}$

Los paneles se forman a petición del país reclamante y deben ser aprobados por el osD, a menos que por consenso este decida no hacerlo. ${ }^{22}$ Son integrados por tres personas independientes altamente calificadas, funcionarios gubernamentales o no, que no pueden ser nacionales de las partes en la diferencia o de los terceros países que, por tener un interés sustancial, participan en la controversia, a menos que las partes acuerden lo contrario. ${ }^{23}$ Sus nombres son propuestos por la Secretaría y solo pueden ser rechazados por razones imperiosas. ${ }^{24} \mathrm{Si}$ no hay acuerdo, son designados por el Director General, en consulta con el Presidente del OSD. ${ }^{25}$

Los paneles tienen el derecho de recabar la información que sea pertinente a la controversia planteada, de cualquier individuo u organización que esté dentro

\footnotetext{
${ }^{20}$ Entendimiento, artículo 3 (6).

21 Artículo XVI (1) del Acuerdo sobre la omc.

${ }^{22}$ Entendimiento, artículo 6.

23 Entendimiento, artículo 8 (1) y (3).

24 Entendimiento, artículo 8 (6).

25 Entendimiento, artículo 8.
} 
de la jurisdicción de un país Miembro, sin otro requisito que el de informar previamente a sus autoridades. A su vez, los países Miembros están legalmente obligados a proveerla y negarse a hacerlo justifica una inferencia negativa por parte del panel respecto de ese Miembro. ${ }^{26}$

El Órgano de Apelación está integrado por siete personas de prestigio reconocido y competencia acreditada en derecho, comercio internacional y la temática de los acuerdos abarcados en general. Ellas no pueden estar vinculadas a gobierno alguno y actúan solo tres, conforme a un turno ya determinado. ${ }^{27}$ Son designadas por el osD, duran en funciones un período de cuatro años, renovable una sola vez, y representan en general la composición de la omc. ${ }^{28}$ Solo las partes pueden recurrir de apelación. Los terceros que hayan notificado al OSD un interés esencial en el asunto pueden presentar comunicaciones por escrito y ser oídos. ${ }^{29}$

El Órgano de Apelación solo examina cuestiones de derecho o las interpretaciones legales que el panel efectúa de un caso. ${ }^{30} \mathrm{El}$ análisis y evaluación de los hechos y de la prueba incumbe exclusivamente al panel. Sin embargo, se ha resuelto que la consideración de la prueba por un panel es una cuestión de derecho y, por lo tanto, revisable por el Órgano de Apelación. Además, se ha opinado que el GATT, el Acuerdo sobre la OMC y sus acuerdos conexos son parte integrante del derecho internacional público y, por lo tanto, están regidos por los principios generales del derecho internacional. ${ }^{31}$ Conforme a ello, el Órgano de Apelación invoca regularmente las reglas de interpretación de la Convención de Viena sobre el Derecho de los Tratados y particularmente su artículo $31 .^{32}$

Las resoluciones de los paneles y del Órgano de Apelación no aplican el principio stare decisis del derecho anglosajón, según el cual los tribunales están obligados a aplicar el derecho establecido en fallos

\footnotetext{
26 Entendimiento, artículo 13.

27 Entendimiento, artículo 17 (1) y (3).

${ }^{28}$ Entendimiento, artículo 17 (2) y (3).

${ }^{29}$ Entendimiento, artículo 17 (4).

30 Entendimiento, artículo 17 (6).

31 Debra Steger cita la opinión del Órgano de Apelación en el caso de la gasolina (documento WT/DS2/AB/R, de 20 de mayo de 1996, p. 17), según la cual las disposiciones del Acuerdo sobre la омC que establecieron dicha organización no pueden ser consideradas "clínicamente aisladas" del derecho internacional público (Steger, 2005).

32 El artículo 31 (1) de la Convención de Viena dice: "Un tratado deberá interpretarse de buena fe conforme al sentido corriente que haya de atribuirse a los términos del tratado en el contexto de estos y teniendo en cuenta su objeto y fin".
}

anteriores sobre unas mismas materias. Los paneles y el Órgano de Apelación de la OMC adoptan sus decisiones libremente, conforme al mérito de los hechos y del derecho aplicable en cada caso. Sin embargo, en la práctica, aunque no sean obligatorios, los fallos anteriores son siempre analizados y considerados prolijamente en cada resolución que se adopta. Constituyen, además, una fuente principal de información para aquellos países que proyectan presentar un reclamo ante la omc.

Los países miembros deben asegurar que sus leyes, reglamentos y procedimientos administrativos sean concordantes con las obligaciones contraídas bajo el Acuerdo de la OMC y acuerdos conexos. ${ }^{33}$ La existencia de una legislación contraria a esos acuerdos — por ejemplo, que sea violatoria del trato nacional o del procedimiento de aplicación de derechos compensatorios-, justifica que un Miembro solicite su modificación o derogación. Ejemplo de ello ha sido el reclamo de varios países, entre ellos Brasil, México y Chile contra Estados Unidos por la llamada Enmienda Byrd del 2000, que modificó la legislación de ese país y autorizó el pago directo de los derechos compensatorios a los denunciantes de importaciones supuestamente subvencionadas o a precios de dumping. El fallo, comentado más adelante, acogió el reclamo y estableció que dicha enmienda era contraria a, e incompatible con, las disposiciones del Acuerdo antidumping (ADP), del Acuerdo sobre subvenciones y medidas compensatorias (SMC) y del GATT de $1994 .{ }^{34}$

La jurisprudencia ha distinguido, sin embargo, entre la legislación contraria e imperativa —que sí sería reclamable - de aquella que, aunque también contraria, es meramente facultativa o discrecional, que no lo sería.

\section{Automaticidad o regla del consenso inverso o negativo}

En contraste con las resoluciones de los órganos del GATT — que para tener validez requerían del consenso de las Partes Contratantes, con lo cual un solo Miembro podía impedir la formación de un panel o la adopción o cumplimiento de un fallo-, en la OMC rige la norma del consenso inverso. Esto significa que las resoluciones del OSD tienen efecto automático a menos que exista consenso por parte de los Miembros en

\footnotetext{
${ }^{33}$ Artículo XVI (4) del Acuerdo sobre la omc.

${ }^{34}$ Documentos WT/DS217/AB/R y WT/DS234/AB/ R y resolución del osD de 27 de enero de 2003.
} 
contra de su adopción. Como es obvio, el consenso de los Miembros para rechazar la formación de un panel, la aprobación de un fallo o la suspensión de concesiones jamás se ha producido. En cambio, en el GATT bastaba el rechazo de esas resoluciones por parte de un Miembro para impedir el consenso, lo que al final obligaba a las partes a negociar una solución política. Esta innovación, entre otras, explica la rapidez y expedición de los procedimientos de la OMC. Tenemos, así, que cuando un país solicita consultas o la formación de un panel arbitral, las resoluciones del OSD a favor o en contra tienen efecto inmediato, a menos que exista consenso en contra. Lo mismo rige para las resoluciones del OSD respecto de los fallos de los paneles arbitrales, ${ }^{35}$ los del Órgano de Apelación, ${ }^{36}$ o los que aprueban suspender concesiones $\mathrm{u}$ otras obligaciones cuando la parte reclamada no cumple lo resuelto por dicho Órgano. ${ }^{37}$ En todos estos casos, las resoluciones pertinentes solo pueden ser revocadas si existe consenso de los Miembros en contra de su adopción.

\section{Preferencia por soluciones no contenciosas}

El primer objetivo del procedimiento es lograr una solución mutuamente aceptable y positiva para las partes en la diferencia. ${ }^{38}$ Conforme a ello, el procedimiento no puede iniciarse por una vía directamente contenciosa sino que debe comenzar, imperativamente, con una mera consulta que se notifica al OSD y el Miembro al cual se dirige está obligado a responder. Esta consulta es confidencial y solo cuando fracasa puede solicitarse la formación de un panel. Sin perjuicio de esto, el procedimiento permite y facilita que las partes puedan, con sujeción a sus reglas —incluida la notificación al OSD - solucionar sus diferencias bilateralmente en cualquiera de sus etapas posteriores.

\section{Costos}

En contraste con otros mecanismos, los procedimientos ante la OMC tienen un bajo costo. Las partes no pagan por administración, gastos de secretaría u honorarios de árbitros. La totalidad de estos costos son asumidos por la Organización con cargo a su presupuesto general. ${ }^{39}$

\footnotetext{
35 Entendimiento, artículo 6 (1).

36 Entendimiento, artículo 16 (4).

37 Entendimiento, artículo 22 (6).

38 Entendimiento, artículo 3 (7).

39 Entendimiento, artículo 8 (11).
}

En las controversias internacionales, sin embargo, los mayores costos son los legales y en esto la oMc también difiere de otras entidades. Desde octubre de 2001 opera el Centro de Asesoría Legal en Asuntos de la омc. Este Centro es un organismo internacional público e independiente, con personalidad jurídica propia, que en enero de 2005 contaba con 37 países miembros (10 de países industrializados y 27 de países en desarrollo). Está basado en Ginebra y su objetivo es proporcionar asesoría legal, a precios razonables, a los países en desarrollo en los temas de la OMC, especialmente en la solución de diferencias. Su actual presidente fue con anterioridad asesor legal de la OMC. Hasta enero de 2005, Honduras, Nicaragua, Ecuador, Perú, Colombia y Venezuela habían recibido la asesoría legal del Centro en algunas de sus controversias ante la omc. En ciertos casos, esta asesoría fue proporcionada directamente por el Centro; en otros, por un asesor legal externo. ${ }^{40}$

\section{Rapidez}

Una vez iniciada una consulta, el procedimiento tiene un cronograma preestablecido y muy estricto, cuyas eventuales prórrogas solo pueden ser autorizadas por el osD. En la práctica, si se le compara con otros procedimientos internacionales, el de la oMc es el más rápido y también el más flexible. Su flexibilidad proviene, entre otros factores, de que se inicia con una gestión no contenciosa - la consulta - y que la mayoría de las consultas terminan con el acuerdo mutuo de las partes o la mera expiración del plazo sin que alguna de las partes solicite la formación de un panel. ${ }^{41}$ La excepción, por lo tanto, es la persistencia de los desacuerdos y su solución por un panel. Inclusive, en algunos casos las partes resuelven de mutuo acuerdo sus diferencias aun después de constituido un panel.

El cronograma es de 60 días para la consulta, ${ }^{42}$ y de seis meses, desde la fecha de la formación del panel, para que este emita su fallo, o informe cuando no hay apelación. Salvo una prórroga del OSD, ${ }^{43}$ en ningún

\footnotetext{
40 www.acwl.ch.

${ }^{41}$ Desde el 1 de enero de 1996 al 22 de octubre de 2004 habían ingresado 317 consultas y solo en 129 casos éstas llevaron a la formación de un panel (véase omc, 2004a, p. 48).

42 Entendimiento, artículo 4 (7).

43 A instancias de la parte reclamante, el trabajo del panel puede suspenderse hasta por 12 meses y, en tal caso, los plazos establecidos en el procedimiento se prorrogarán por el período de esa suspensión; pero si los trabajos se suspendieran por más de 12 meses cesarán las funciones del panel. Véase Entendimiento, artículo 12 (12).
} 
caso el período que transcurre entre el establecimiento del panel y la distribución del informe por el OSD a los Miembros puede exceder de nueve meses, y de doce meses cuando hay apelación. ${ }^{44}$ Cuando hay apelación, el fallo debe distribuirse dentro de los 60 días desde que se notifica formalmente la decisión de apelar. ${ }^{45}$

Una vez adoptado el fallo por el panel o el Órgano de Apelación, el Miembro afectado deberá informar al OSD su propósito de cumplir con las decisiones adoptadas. De no cumplirlas de inmediato, deberá hacerlo dentro de un término prudencial que normalmente no podrá exceder de 15 meses desde la fecha del fallo del panel o del Órgano de Apelación. Sin embargo, cuando el panel o el Órgano de Apelación haya prorrogado los plazos para la emisión de los fallos respectivos, el plazo adicional se añadirá al período de 15 meses con la salvedad de que, a menos que las partes convengan en que concurren circunstancias excepcionales, el período total no podrá exceder de 18 meses desde la mencionada fecha. ${ }^{46}$

\section{Cumplimiento o ejecución}

Si el panel o el Órgano de Apelación resuelve que la medida reclamada es incompatible con un acuerdo abarcado, recomendará que el Miembro afectado la ponga en conformidad con ese acuerdo, y podrá sugerir la forma de hacerlo. ${ }^{47}$

Si hay desacuerdo respecto de las medidas de cumplimiento o su compatibilidad con un acuerdo abarcado, esa diferencia se resolverá conforme al mismo procedimiento y, de ser posible, por el panel que intervino originalmente y dentro de los 90 días tras serle sometido el asunto. ${ }^{48} \mathrm{Si}$ el Miembro afectado o perjudicado por el fallo no cumple dentro del plazo prudencial con las medidas acordadas, ese Miembro, si así se lo pide la otra parte, deberá negociar una compensación mutuamente aceptable. La compensación es, además, voluntaria, en el sentido de que el país puede negarse, en cuyo caso vale la suspensión indefinida de las concesiones hasta que el país cumpla, y en caso de otorgarse, debe ser compatible con los acuerdos pertinentes. ${ }^{49} \mathrm{Si}$ dentro de 20 días de expirado el plazo

\footnotetext{
44 Entendimiento, artículo 12 (8) y (9) y artículo 20.

45 Entendimiento, artículo 17 (5).

46 Entendimiento, artículo 21 (3).

47 Entendimiento, artículo 19 (1).

48 Entendimiento, artículo 21 (5).

49 Entendimiento, artículo 22 (1).
}

prudencial acordado ello no ha ocurrido, cualquiera de las partes que haya recurrido al procedimiento de solución de diferencias podrá pedir al OSD que se suspendan temporalmente al Miembro afectado las concesiones $\mathrm{u}$ otras obligaciones resultantes de los acuerdos abarcados. ${ }^{50}$

Las suspensiones o represalias se autorizarán por el osD hasta que se haya suprimido la medida declarada incompatible con el acuerdo abarcado o hasta que el Miembro afectado ofrezca solucionar la anulación o menoscabo o llegar a una solución mutuamente satisfactoria. ${ }^{51}$ Sin embargo, el Miembro afectado puede impugnar el nivel de la suspensión propuesta o los procedimientos seguidos, en cuyo caso la diferencia se someterá al arbitraje del panel original si estuviera disponible o, de no estarlo, de un árbitro designado por el Director General. ${ }^{52}$ Por otra parte, el nivel de suspensión de concesiones u otras obligaciones que autorice el OSD debe ser equivalente al nivel de anulación o menoscabo del acuerdo infringido. ${ }^{53}$

En los diez años de vigencia de la omc ha habido solo seis casos en que el cumplimiento de una resolución final del Órgano de Apelación ha sido cuestionado y ha requerido que el OSD autorice la suspensión de concesiones u otras obligaciones en contra del miembro infractor. De estos seis casos, tres han involucrado, según se indica más adelante, a países latinoamericanos.

\section{Algunas insuficiencias}

Una de las insuficiencias del procedimiento es que este no contempla el otorgamiento de medidas precautorias o provisionales que aseguren a la parte reclamante los resultados de la controversia. Además, las decisiones finales de los paneles o del Órgano de Apelación solo rigen para el futuro y no desde la fecha en que se cometió la infracción recurrida.

Respecto a las compensaciones o suspensión de concesiones u otras obligaciones que podrán imponerse a un Miembro infractor para dar cumplimiento a las resoluciones del OSD, estas deben ser equivalentes al nivel de la anulación o menoscabo de los acuerdos infringidos ${ }^{54} \mathrm{El}$ problema con esta exigencia de proporcionalidad es que tiene un impacto mínimo sobre

\footnotetext{
${ }^{50}$ Entendimiento, artículo 22 (2).

51 Entendimiento, artículo 22 (8).

52 Entendimiento, artículo 22 (6).

53 Entendimiento, artículo 22 (4).

54 Entendimiento, artículo 22 (4).
} 
un país industrializado cuando el reclamante es un país en desarrollo. Además, la suspensión de concesiones aumenta los aranceles aplicables al país sancionado y, por consiguiente, eleva el precio de las importaciones que deberán pagar los consumidores del país importador. Finalmente, quizás la limitación más seria es que el OSD carece de imperio, esto es, de la facultad de aplicar medidas coercitivas para hacer cumplir sus decisiones. Esta limitación debe contrastarse con la norma del Centro Internacional de Arreglo de Diferencias Relativas a Inversiones (CIADI), que otorga valor ejecutivo dentro de todos los Estados Miembros de esa entidad a los laudos arbitrales dictados conforme a las disposiciones del convenio constitutivo del CIADI. 55

\section{Comparación con otros mecanismos}

En comparación con otros procedimientos de solución de controversias internacionales, el de la omc es el más eficiente. Es un procedimiento o código de reglas objetivo, rápido, predecible, de bajo costo y que — pese a las limitaciones ya mencionadas - responde de manera efectiva a las necesidades de los países en desarrollo. Con anterioridad, era difícil o improbable que un reclamo comercial de un país en desarrollo pudiera prosperar ante los tribunales de un país industrializado o, durante sus primeras décadas, ante los órganos del GaTT. El cambio más fundamental ha sido el reemplazo de un sistema en que predominan consideraciones políticas, por uno administrado por órganos independientes que deben aplicar un estatuto jurídico que reconoce y protege la igualdad de derechos de todos sus Miembros. Esto significa - como veremos-que actualmente cualquier país en desarrollo puede reclamar con éxito el incumplimiento por un país industrializado de sus obligaciones con la OMC.

Dos ejemplos, entre muchos, que no habrían sido posibles bajo el GATT, son ilustrativos de los beneficios que la OMC ha traído a los países latinoamericanos.

El primero fue el reclamo de Costa Rica contra Estados Unidos por sus restricciones y salvaguardias a las importaciones de productos textiles. El Panel acogió el reclamo y resolvió que Estados Unidos no demostró que las exportaciones de Costa Rica fueran un daño serio o amenaza real o actual a su industria interna y que, por lo tanto, sus restricciones infringie-

\footnotetext{
55 Véase el artículo 54 del Convenio sobre Arreglos de Diferencias Relativas a Inversiones entre Estados y Nacionales de otros Estados que dio origen al CIADI.
}

ron los artículos 6.2 y 6.4 del Acuerdo Textil. Además, al no otorgar trato preferente a las reexportaciones de Costa Rica, las medidas estadounidenses infringieron el artículo 6.6 d) del mismo Acuerdo. ${ }^{56}$

El segundo fue el reclamo del Perú contra las Comunidades Europeas, por impedirle utilizar la designación "sardinas" en sus exportaciones de esta especie, aduciendo que no coincidía con la descripción europea; este reclamo fue acogido por el Órgano de Apelación. El fallo resolvió que las normas europeas infringían el artículo 2.4 del Acuerdo sobre Obstáculos Técnicos al Comercio y el artículo XVI(4) del Acuerdo sobre la OMC, que exige a los países asegurar que su legislación, reglamentación y procedimientos administrativos guarden conformidad con las obligaciones impuestas por acuerdos conexos como el mencionado. ${ }^{57}$

El dinamismo y la amplia jurisdicción del procedimiento de la OMC contrastan con aquellos de la Corte Internacional de Justicia (CIJ); del CIADI, cuyo Consejo de Administración está encabezado por el Presidente del Banco Mundial, y de los que administró el GATT hasta 1995.

La CIJ administra exclusivamente controversias entre Estados y estos pueden formular reservas o rechazar su jurisdicción obligatoria. La OMC también administra controversias entre Estados pero, en contraste con la CIJ, no admite reservas ${ }^{58}$ ni que pueda cuestionarse la jurisdicción de sus órganos de solución de controversias. Distinta es la situación de la CIJ, donde 58 de sus miembros, incluidos cuatro de los cinco miembros permanentes del Consejo de Seguridad de las Naciones Unidas han rechazado su jurisdicción obligatoria. ${ }^{59} \mathrm{Su}$ desempeño tampoco ha sido trascendente. En efecto, desde 1947 hasta 2004, esto es, en más de 57 años, la cı ha dictado solamente 61 fallos y 23 opiniones consultivas.

Respecto del CIADI, su jurisdicción se limita a las controversias entre algunos de sus 148 Estados Miembros y un nacional o inversionista de esos Estados. Desde su creación, en octubre de 1966, hasta el fin del año fiscal 2004, tenía registrados 159 casos y los juicios concluidos o pendientes eran $86 .^{60}$

\footnotetext{
${ }^{56}$ Documento WT/DSB/M/29 y resolución del osD de 25 de febrero de 1997.

${ }^{57}$ Documento DS/231/AB/R y resolución del OsD de 26 de noviembre de 2002.

58 Artículo XVI(5) del Acuerdo sobre la omc.

${ }^{59}$ Véase Petersmann (1997, p.23.)

${ }^{60}$ CIADI $(2004$, p.4).
} 
En cuanto al GATT, en casi 50 años —desde 1948 a $1994-$, se resolvieron 196 reclamos. ${ }^{61}$ Las anteriores cifras deben compararse con las 317 consultas in- gresadas y 129 paneles formados en la OMC en ocho años, desde 1996 hasta el 22 de octubre de 2004, según se detalla más adelante. ${ }^{62}$

\section{IV}

\section{La política estadounidense}

La política estadounidense desde la época del GatT hasta la OMC ha sido de consistente apoyo al libre comercio y rechazo a las prácticas desleales. ${ }^{63}$ Esta política ha estado fuertemente influenciada por la dramática experiencia de la crisis de 1930 y las erradas políticas que la precipitaron y que incluyeron, entre otras, a la ley Smoot-Hawley, ejemplo histórico del proteccionismo comercial más primitivo. ${ }^{64}$

Sin perjuicio de lo anterior, fuertes grupos de presión, con gran influencia política, han perpetuado la protección de industrias - particularmente en el sector agrícola- que no podrían haber subsistido en un verdadero régimen de libre comercio. ${ }^{65}$ Ejemplos de esto son, entre otros, la industria del azúcar ${ }^{66}$ y del algodón. Paralelamente, la contingencia política ha llevado a los gobiernos a adoptar, de tiempo en tiempo, medidas de protección en favor de determinadas industrias. Ejemplo de ello fue la reciente alza de los aranceles sobre las importaciones de acero, la cual motivó un reclamo ante la omc que comentamos más adelante.

\footnotetext{
61 OMC (1995, pp. 771-787).

62 OMC (2004a, p. 48).

63 Durante las negociaciones de la Ronda Uruguay, Estados Unidos aceptó derogar la sección 301 de su ley de comercio de 1974 que lo autorizaba para aplicar represalias unilaterales en contra de aquellas prácticas de otros países consideradas restrictivas o discriminatorias para el comercio de Estados Unidos. Bajo esta ley fueron aplicadas represalias a países latinoamericanos en no menos de once casos. Brasil fue uno de los países más afectados por estas medidas. (Véase Husted, 1995, p. 261).

${ }^{64}$ La ley Smoot-Hawley de 1930 elevó los aranceles comerciales de Estados Unidos a los niveles más altos de su historia. Como consecuencia hubo una drástica caída del comercio exterior y se aceleró la depresión. (Véase Columbia Electronic Encyclopedia, 2003.)

${ }^{65} \mathrm{El}$ apoyo a la agricultura en los países de la organización de cooperación y Desarrollo Económicos (OCDE) fue estimado en 350.000 millones de dólares en 2003, de los cuales Estados Unidos, la Unión Europea y Japón representaron colectivamente cuatro quintos. (Véase ocDE, 2004).

${ }^{66}$ La protección a la industria del azúcar sería un obstáculo a la aprobación de un acuerdo de libre comercio entre Estados Unidos y los países de Centroamérica. (Véase Barrionuevo y Becker, 2005, p. C1.)
}

Aunque el apoyo al libre comercio se mantiene en lo sustancial, los fallos adversos de los órganos de la OMC han hecho surgir, como veremos, fuertes cuestionamientos de distintos sectores de Estados Unidos a sus procedimientos y resoluciones.

Sin perjuicio de lo mencionado, un informe del gobierno estadounidense de 1997 entregó su irrestricto apoyo al procedimiento de la oMc y, concretamente, al trámite de las consultas, señalando: las nuevas reglas del procedimiento de disputas nos permiten obtener con frecuencia el cumplimiento de los acuerdos de la OMC sin que jamás tengamos que acudir a la resolución de un panel. A continuación, el informe apoyó su conclusión con la cita de siete casos que fueron resueltos de esta manera. ${ }^{67}$

Por otra parte, hasta hace poco, la opinión pública y sectores políticos estadounidenses no concebían que las decisiones de sus autoridades administrativas o judiciales en materias comerciales o de inversiones pudieran ser revocadas o modificadas por tribunales internacionales. Cuando esto sucede, surge un ambiente de rechazo hacia lo que se percibe como una intromisión inaceptable en la soberanía del país. Este cambio se produce muy gradualmente. Primero, con motivo de algunas resoluciones de los tribunales arbitrales establecidos bajo el acuerdo bilateral de libre comercio de 1987 con Canadá y, posteriormente, con algunos de los fallos de los tribunales establecidos bajo el Tratado de Libre Comercio de América del Norte, del CIADI y, finalmente, de la OMC. Algunas de estas experiencias han provocado hostilidad hacia las jurisdicciones internacionales que son percibidas como contrarias a la soberanía nacional y se argumenta que la interpretación de la legislación de Estados Unidos solo corresponde a sus propios tribunales y no a burócratas sin

\footnotetext{
67 Oficina del Representante de Comercio de Estados Unidos, Informe sobre las prioridades de expansión del comercio, citado por Horlick (1998, p. 685.) Cita en cursiva traducida del inglés por el autor.
} 
rostro, escondidos en Ginebra. Estas reacciones y defensas de la soberanía, curiosamente, coinciden con las antiguas experiencias - ya en parte superadas - que nuestra región ha tenido con el Fondo Monetario Internacional, las condicionalidades de los organismos financieros internacionales y las políticas unilaterales de algunos países.

Las actuales críticas fueron enunciadas al discutirse el acuerdo de la OMC con la afirmación de que las decisiones de las ciudadanías y sus legítimos representantes quedarán seriamente restringidas por una burocracia y órganos de solución de disputas ubicados en Ginebra que trabajarán en secreto sin las garantías de debido proceso y la participación ciudadana que establecen las legislaciones y judicaturas nacionales. ${ }^{68}$

En concordancia con estas reservas, una resolución del Senado de marzo de 2003, conocida como "propuesta Dole", estableció una Comisión de cinco miembros que deberá revisar las resoluciones de los paneles y del Órgano de Apelación adversas a Estados Unidos e informar de ello al gobierno. Concretamente, la Comisión deberá determinar si los mencionados órganos de la omc han excedido su autoridad o mandato, han agregado obligaciones o reducido los derechos de Estados Unidos bajo los acuerdos de Marrakech, han actuado arbitraria o caprichosamente o se han desviado de la norma del artículo 17.6 del Acuerdo ADP (que hace prevalecer en las investigaciones antidumping las resoluciones de las entidades nacionales sobre aquellas de los órganos de la OMc). ${ }^{69}$

Una resolución posterior de la Cámara de Representantes rechazó el fallo del Órgano de Apelación que estableció que las salvaguardias a las importaciones de acero no eran compatibles con los acuerdos de la OMC. ${ }^{70}$ Sin embargo, con posterioridad, el gobierno estadounidense ha dado cumplimiento a dicho fallo.

Una crítica más general provino de ambas ramas del Congreso respecto de la interpretación de los acuerdos antidumping (ADP), sobre subsidios y medidas compensatorias (SMC) y sobre salvaguardias (SVG). Se recomendó al Presidente que se asegurara de que en los procedimientos de la OMC se observaran o aplicaran las diversas medidas que allí se mencionan, incluyendo, entre otras, que el artículo 17.6 del Acuerdo ADP —que hace prevalecer las decisiones de las jurisdicciones na-

\footnotetext{
68 Testimonio de Ralph Nader ante el $104^{\circ}$ Congreso de Estados Unidos, en 1994. La cita en cursiva fue traducida del inglés por el autor.

${ }^{69}$ Resolución del Senado No 676 , de 20 de marzo de 2003.

${ }^{70}$ Resolución de la Cámara de Representantes No 445, de 18 de noviembre de 2003 .
}

cionales sobre las de los órganos de la OMC - se aplique no solo a las investigaciones antidumping sino también a las investigaciones sobre subvenciones y salvaguardias. ${ }^{71}$ Según un autor, con el cual concordamos, esta última interpretación no tendría base legal. ${ }^{72}$

Contradice las anteriores aprensiones el informe de 30 de julio de 2003 de la Oficina General de Contabilidad estadounidense (General Accounting OfficeGAO). Según ese informe, la mayoría de los expertos consultados, tanto del sector público como del privado, opina que la OMC no habría excedido su autoridad en la aplicación del Acuerdo ADP, que todos sus Miembros son tratados de la misma manera y que no se les habrían impuesto nuevas obligaciones o reducido sus derechos. Sin embargo, las reglas sobre causalidad y circunstancias imprevistas en materia de salvaguardias fueron consideradas confusas. ${ }^{73}$

Las críticas desde círculos académicos y profesionales también han sido fuertes y persistentes. Una opinión muy difundida, pero no apoyada por la realidad, es que los paneles han estado resolviendo casi universalmente en contra de los Estados Unidos durante muchos años. ${ }^{74}$ Sin embargo, el citado informe de la GAO afirma que 11 de 13 reclamos de países Miembros en contra de la compatibilidad de distintas leyes comerciales de Estados Unidos con la normativa de la OMC fueron rechazadas y que en 21 determinaciones de autoridades locales en investigaciones antidumping o sobre subvenciones, el número de rechazos contra las determinaciones estadounidenses fue equivalente al número de rechazos contra las determinaciones de otros países. ${ }^{75}$

Un rechazo frecuente es el que despierta el llamado "activismo judicial", o adopción por los órganos de la OMC de resoluciones sobre materias no legisladas, ambiguas, contradictorias o que no fueron acordadas en Marrakech. Según los críticos, los paneles o el Órgano de Apelación deberían abstenerse de resolver materias de esta naturaleza y entregar su resolución a los órganos políticos de la omc. ${ }^{76}$

Los anteriores comentarios no han cambiado, sin embargo, el apoyo de sucesivos gobiernos estadounidenses a la OMC, que se ha manifestado, entre otras

\footnotetext{
${ }^{71}$ Resolución concurrente del Senado y la Cámara de Representantes $\mathrm{N}^{\circ} 243$, de 15 de julio de 2003.

72 Jackson (1999, p. 90).

73 GAO (2003, p. 30).

74 Ragosta, Joneja y Zeldovich (2003, p. 750). Cita traducida del inglés por el autor.

75 GAO (2003, p. 12).

${ }^{76}$ Ragosta, Joneja y Zeldovic (2003, p. 751).
} 
conductas, en su cumplimiento - aunque con atrasos y cuestionamientos discutibles - de las resoluciones adversas. A ello se agrega que Estados Unidos ha sido el mayor usuario del sistema. Hasta mayo de 2005, había participado como reclamante, reclamado o tercero, con una sola excepción, en todas las controversias resueltas por el Órgano de Apelación. ${ }^{77}$ Este hecho por sí solo confirmaría, en nuestra opinión, el apoyo de Estados Unidos a la omc.
Una perspectiva estadounidense bastante equilibrada ha sido la del profesor John Jackson. Él cita dos opiniones que, según estima, resumirían el actual debate. La primera sería del jefe demócrata Tip O’Neill, para quien "todo en política es local". La segunda sería del economista Peter F. Drucker, para quien "todo en economía es internacional". Para Jackson, conciliar estas dos percepciones es el futuro gran desafío de las relaciones comerciales internacionales. ${ }^{78}$

\section{V}

\section{Las controversias más frecuentes}

Las controversias más frecuentes en que han participado los países latinoamericanos, como demandantes o como demandados, han sido generalmente sobre la aplicación de los acuerdos conexos sobre subvenciones y medidas compensatorias (SMC), antidumping (ADP), sobre salvaguardias (ASG), así como de determinadas secciones del GATT de 1994. Estos acuerdos son parte integrante del Acuerdo sobre la OMC y vinculantes para todos sus Miembros. ${ }^{79}$ Coincidentemente, las críticas de algunos sectores estadounidenses a las resoluciones de los órganos de la OMC han estado dirigidas principalmente, como veremos, a la forma como se han aplicado e interpretado estos tres acuerdos conexos.

\section{Acuerdo sobre subvenciones y medidas compensatorias (sMc)}

Existe subvención cuando hay una contribución financiera de un gobierno u organismo público en el territorio de un Miembro o alguna forma de sostenimiento de los ingresos o de los precios y con ello se otorga un beneficio. ${ }^{80}$ Subvenciones prohibidas son las subvenciones supeditadas de jure o de facto a los resultados de exportación y las supeditadas al empleo de productos nacionales con preferencia a los importados, en ambos casos como condición única o entre otras varias condiciones. ${ }^{81}$ A los Miembros les está prohibido originar, mediante algunas de las subvenciones mencionadas, efectos desfavorables que causen daño

77 Smith (2004), citado en Shaffer (2005).

78 Jackson (1999, p. 104).

79 Artículo II (2) del Acuerdo sobre la omc.

${ }^{80}$ Artículos 1.1 y 1.2 del Acuerdo SMC.

${ }^{81}$ Artículo 3.1 a) y b) del Acuerdo smC. a la producción nacional, o anulación o menoscabo de las ventajas resultantes directamente del GATT de 1994 (en particular de las concesiones ya consolidadas) o perjuicio grave a los intereses de otro Miembro. ${ }^{82}$

Los Miembros solamente pueden aplicar derechos compensatorios después de iniciada y concluida una investigación que haya acreditado la existencia, grado y efectos de la supuesta subvención. Las investigaciones deben iniciarse a solicitud escrita de una rama de la producción nacional o, excepcionalmente, por la autoridad, cuando esta tenga pruebas suficientes de la existencia de una subvención, del daño y de la relación causal entre las importaciones subvencionadas y el supuesto daño. ${ }^{83}$ Por derecho compensatorio se entiende "un derecho especial percibido para neutralizar cualquier subvención concedida directa o indirectamente a la fabricación, producción o exportación de un producto, de conformidad con lo dispuesto en el párrafo 3 del artículo VI del GATT de 1994". ${ }^{84}$

\section{Acuerdo antidumping (ADP)}

El Acuerdo ADP establece que las medidas antidumping se aplicarán en las circunstancias previstas en el artículo VI del GATT de $1994,{ }^{85}$ y en virtud de investigaciones

\footnotetext{
82 Artículo 5 del Acuerdo SMC.

83 Artículos 10 y 11 del Acuerdo SMC.

${ }^{84}$ Nota 36 al Artículo 10 del Acuerdo smC. El artículo VI del GATT 1994 se refiere a los derechos antidumping y derechos compensatorios. ${ }^{85}$ Las circunstancias que menciona el artículo VI del GATT son que el producto introducido al mercado de otro país a un precio inferior a su valor normal cause o amenace causar un daño importante a una rama de producción existente en una parte contratante o retrase de manera importante la creación de una rama de producción nacional.
} 
iniciadas y realizadas en conformidad con el mismo Acuerdo. ${ }^{86}$ Para tales efectos, considera que un producto es objeto de dumping "si se introduce en el mercado de otro país a un precio inferior a su valor normal, cuando su precio de exportación al exportarse de un país a otro sea menor que el precio comparable, en el curso de operaciones normales, de un producto similar destinado al consumo en el país exportador". ${ }^{87} \mathrm{En}$ términos similares al Acuerdo SMC, el Acuerdo ADP exige, como requisito para la aplicación de derechos compensatorios, la realización de una investigación previa por una rama de la producción nacional o, por excepción y cuando las circunstancias así lo justifiquen, por la propia autoridad. ${ }^{88}$

Horas antes de que concluyera la Ronda Uruguay, Estados Unidos logró incorporar una disposición que ha generado bastante controversia. ${ }^{89} \mathrm{Se}$ trata del artículo 17.6 que establece que los paneles, al evaluar los hechos en un reclamo ADP, deberán determinar si las autoridades locales han establecido adecuadamente los hechos y realizado una evaluación imparcial y objetiva de ellos. Si los paneles así lo establecen, esa evaluación no podrá invalidarse, aunque el panel hubiera llegado a una evaluación distinta. En otras palabras, prevalece la evaluación de los hechos realizada por las autoridades locales sobre aquella que hagan los tribunales de la omc. Agrega el artículo mencionado que el panel deberá, además, interpretar las disposiciones pertinentes del Acuerdo ADP conforme a las reglas consuetudinarias del derecho internacional público. Sin embargo, si concluye que esas disposiciones se prestan a diversas interpretaciones admi-

\footnotetext{
86 Artículo 1 del Acuerdo ADP.

87 Artículo 2.1 del Acuerdo ADP.

${ }^{88}$ Artículos 1 y 5 del Acuerdo ADP.

${ }^{89}$ Petersmann (1997, p. 54, nota 98).

90 Artículo 17.6 ii) del Acuerdo ADP.

${ }^{91}$ Una de las medidas de salvaguardia que menciona el artículo XIX es la siguiente: cuando, como consecuencia de la evolución imprevista de las circunstancias y por efecto de las obligaciones, incluidas las concesiones arancelarias, contraídas por una parte contratante, las importaciones de un producto en el territorio de esa parte
}

sibles, deberá preferir aquella interpretación que favorezca la medida adoptada por las autoridades locales. ${ }^{90}$

\section{Acuerdo sobre salvaguardias (ASG)}

El ASG reglamenta la aplicación de las medidas de salvaguardia previstas en el artículo XIX del GATT de $1994^{91}$ y establece que un Miembro solo podrá aplicar tales medidas si dicho Miembro ha determinado, con arreglo al ASG, que las importaciones de un producto en su territorio han aumentado en tal cantidad, en términos absolutos o en relación con la producción nacional, y se realizan en condiciones tales que causan o amenazan causar un daño grave a la rama de la producción nacional que entrega productos similares o directamente competidores. El ASG, sin embargo, no menciona "las circunstancias imprevistas" que podrían haber causado las importaciones excesivas conforme al artículo XIX del GATT, lo cual ha generado controversias respecto de cuál disposición o acuerdo prevalece.

Las medidas solo pueden adoptarse después de una investigación por las autoridades competentes de ese Miembro y con arreglo a un procedimiento público preestablecido. ${ }^{92} \mathrm{Su}$ aplicación, además, será solamente en tanto sean necesarias para prevenir o reparar el daño grave y facilitar el reajuste ${ }^{93}$ y no pueden durar más de cuatro años, salvo que haya prórroga. ${ }^{94} \mathrm{El}$ Acuerdo estableció un Comité de Salvaguardias bajo la autoridad del Consejo de Comercio de Mercancías que vigila y supervisa su aplicación. ${ }^{95}$

\footnotetext{
contratante han aumentado en tal cantidad y se realizan en condiciones tales que causan daño o amenazan causar daño grave a los productores nacionales de productos similares o directamente competidores en ese territorio, dicha parte contratante podrá, en la medida y durante el tiempo que sean necesarios para prevenir o reparar ese daño, suspender total o parcialmente la obligación contraída con respecto a dicho producto o retirar o modificar la concesión.

92 Artículo 3 del ASG.

93 Artículo 5 (1) del ASG.

94 Artículo 7 (1) del ASG.

95 Artículo 13 (1) del ASG.
} 


\section{VI}

\section{La experiencia de América Latina y el Caribe ${ }^{96}$}

Desde el 1 de enero de 1996 hasta el 22 de octubre de 2004, habían ingresado 317 consultas a la OMC que llevaron a la formación de 129 paneles para 159 disputas. ${ }^{97}$ Estos paneles emitieron 90 fallos de los cuales 59 fueron apelados y, por lo tanto, en 31 casos las partes aceptaron lo resuelto por el panel..$^{98}$ Respecto de las consultas, 188 terminaron por acuerdo mutuo de las partes o, las diferencias, por distintas razones, fueron resueltas y no fue necesaria la formación de un panel.

De estas consultas, la mayoría fueron hechas por los países industrializados, 204 como reclamantes y 191 como reclamados. Los países en desarrollo, en cambio, formularon 136 consultas y fueron objeto de $122 .{ }^{99}$

Las consultas más frecuentes han sido en materia de antidumping, de subvenciones y medidas compensatorias, y de salvaguardias.

Respecto de antidumping, desde 1995 los países que han aplicado el mayor número de medidas han sido India (279), Estados Unidos (211), la Unión Europea (193) y Argentina (139); y han sido objeto del mayor número de estas medidas China (272), la Unión Europea y sus países miembros (213) y la República de Corea (110). ${ }^{100}$

Respecto de subvenciones y medidas compensatorias, durante el período 1995- 2003, fueron notificadas 168 investigaciones y las principales fueron aplicadas por Estados Unidos (69) y la Unión Europea (42). ${ }^{101}$ Por otra parte, los países que han aplicado el mayor número de salvaguardias han sido India (8), Estados Unidos (6) y Chile, la República Checa y Filipinas, con 5 cada uno.

En cuanto al cumplimiento de los fallos de los paneles o del Órgano de Apelación, en general, la gran mayoría se ha cumplido dentro del plazo razonable establecido por el artículo 21.3 del Entendimiento. ${ }^{102}$

\footnotetext{
${ }^{96}$ Las cifras de esta sección tienen ligeras discrepancias con las dadas en otras partes de este documento debido a que las fuentes provienen de períodos distintos.

97 омс (2004a, p. 48, nota 93).

98 омс (2004a, p .49, nota 96).

99 омс (2004a, p. 49, nota 95).

100 омс (2004a, pp. 38 у 39, nota 67).

101 омC (2004a, p. 39, nota 68).

102 омС (2004a, p. 49, nota 97), y Entendimiento, artículo 21(3).
}

La excepción han sido los casos en que las partes no estuvieron de acuerdo y la parte favorecida debió solicitar la autorización del osD para suspender concesiones u otras obligaciones respecto del infractor. Desde 1995, estos casos han sido seis y los siguientes tres han involucrado a países latinoamericanos: ${ }^{103}$

- Demandas de Estados Unidos, Ecuador, Guatemala, Honduras, México y otros países contra las restricciones a las importaciones de bananos de las Comunidades Europeas.

- Demandas de Canadá contra Brasil por las subvenciones al financiamiento de las exportaciones de su aviación civil.

- Demandas de Brasil contra Canadá por las subvenciones a los créditos de exportación y garantías de préstamos a su aviación civil. ${ }^{104}$

\section{Las consultas}

Una consecuencia de la estructura gradual del procedimiento y la preferencia por soluciones no contenciosas es que una gran proporción de las consultas del período 1995-marzo 2005 terminaron con el acuerdo de las partes, sin que fuera necesaria la formación de un panel. Este resultado ha sido destacado por Estados Unidos y la Unión Europea como uno de los grandes éxitos del procedimiento.

Brasil y Argentina han sido los mayores usuarios latinoamericanos del procedimiento de consultas. Brasil ha sido solicitante de 22 y solicitado de 12 consultas, y Argentina ha sido solicitante de 9 y solicitado de 15 consultas. ${ }^{105}$

\section{Las controversias resueltas por el Órgano de Apelación}

Desde el 20 de mayo de 1996 al 19 de mayo de 2005 fueron 68 las controversias resueltas mediante fallos o

\footnotetext{
103 Véase más atrás en el presente artículo el último párrafo de la sección III, apartado 7.

104 OMC (2004a, p. 49, nota 97).

105 OMC (2004a, p. 48).
} 
informes definitivos del Órgano de Apelación de la OMC. ${ }^{106}$

Aproximadamente un tercio (22) de estos 68 fallos recayeron en controversias en que los países latinoamericanos fueron demandantes o demandados, ${ }^{107} \mathrm{y}$ en tres de estos 22 casos las controversias fueron entre países latinoamericanos exclusivamente. Por lo tanto, las restantes 19 se produjeron entre países latinoamericanos y países no latinoamericanos.

De las 19 controversias mencionadas, hubo ocho en las que los países latinoamericanos interpusieron sus demandas individualmente y cinco en las que sus demandas fueron interpuestas junto con otros países.

Por otra parte, hubo seis controversias en que los países latinoamericanos fueron los demandados.

El detalle de estas controversias se expone a continuación.

a) Demandas individuales de países latinoamericanos y del Caribe

Estas demandas fueron las ocho siguientes y los fallos favorecieron a los demandantes en todos los casos, excepto dos: ${ }^{108}$

i) Costa Rica contra Estados Unidos por sus restricciones a las importaciones de productos textiles; el fallo favoreció a Costa Rica. ${ }^{109}$

ii) Brasil contra las Comunidades Europeas por las restricciones a las importaciones de productos avícolas; el fallo favoreció a las Comunidades Europeas. ${ }^{110}$

iii) Brasil contra Canadá por los subsidios a la exportación de su aviación civil; el fallo favoreció a Brasil. ${ }^{111}$

iv) Perú contra las Comunidades Europeas por el impedimento de utilizar la denominación "sardinas" en sus exportaciones a esa región; el fallo favoreció a Perú. ${ }^{112}$

\footnotetext{
106 www.wto.org/english/tratop/_e/dispu_e/ab_reports_e.html.

107 Dentro de estos 22 fallos se incluye el del 20 de abril de 2005 que resolvió la controversia de Antigua y Barbuda con Estados Unidos sobre suministro transfronterizo de servicios de apuestas y juego ( documento del Órgano de Apelación WT/DS267/AB/R.).

108 Las excepciones fueron la demanda de Brasil en contra de las Comunidades Europeas por sus restricciones a las importaciones de productos avícolas, y de Antigua y Barbuda contra Estados Unidos por sus restricciones transfronterizas a los servicios de apuestas y juegos. Los fallos favorecieron a las Comunidades Europeas y Estados Unidos, respectivamente.

109 Documento WT/DS24/AB/R de 20 de marzo de 1997. Este documento y otros con signaturas similares que se citan en adelante correponden al Órgano de Apelación.

110 Documento WT/DS69/AB/R de 23 de julio de 1998.

111 Documento WT/DS70/AB/R de 20 de agosto de 1999.

112 Documento WT/DS231/AB/R de 23 de octubre de 2002.
}

v) Brasil contra las Comunidades Europeas por la aplicación de medidas antidumping a las exportaciones de tubos de acero; el fallo favoreció a Brasil. ${ }^{113}$

vi) Argentina contra Estados Unidos por la aplicación de medidas antidumping a las importaciones de tubos de acero argentinas para la industria petrolífera; el fallo favoreció a Argentina. ${ }^{114}$

vii) Brasil contra Estados Unidos por los subsidios a la industria del algodón; el fallo favoreció a Brasil. ${ }^{115}$

viii) Antigua y Barbuda contra Estados Unidos por restricciones al suministro transfronterizo de servicios de apuestas y juegos; el fallo favoreció a Estados Unidos. ${ }^{116}$

b) Demandas de países latinoamericanos junto con otros países

Estas demandas fueron cinco y todos los fallos favorecieron a los demandantes:

i) Brasil y Venezuela contra Estados Unidos por sus restricciones a las importaciones de gasolina. ${ }^{117}$

ii) Ecuador, Guatemala, Honduras, México y Estados Unidos contra las Comunidades Europeas por sus restricciones a las importaciones de bananos. ${ }^{118}$

iii) Brasil, Chile, México, las Comunidades Europeas y otros países contra Estados Unidos por la llamada Enmienda Byrd. ${ }^{119}$

iv) Brasil, las Comunidades Europeas y otros países contra las salvaguardias de Estados Unidos a las importaciones de acero. ${ }^{120}$

v) Brasil, Australia y Tailandia contra las Comunidades Europeas por sus subsidios al azúcar. ${ }^{121}$

c) Controversias en que los países latinoamericanos han sido los demandados

Estas controversias han sido seis $\mathrm{y}$, con una sola excepción, los fallos han sido todos desfavorables a los demandados:

i) Filipinas contra Brasil por la aplicación de medidas compensatorias a las importaciones de coco desecado de Filipinas; el fallo favoreció a Brasil. ${ }^{122}$

\footnotetext{
113 Documento WT/DS219/AB/R de 18 de agosto de 2003.

114 Documento WT/DS268/AB/R de 17 de diciembre de 2004.

115 Documento WT/DS/267/AB/R de 21 de marzo de 2005.

116 Documento WTDS285/AB/R de 20 de abril de 2005.

117 Documento WT/DS2/AB/R, de 20 de mayo de 1996.

118 Documento WT/DS27/AB/R, de 25 de septiembre de 1997.

119 Documento WT/DS217/AB/R, de 27 de enero de 2003.

${ }^{120}$ Documento WT/DS248/AB//R de 10 de diciembre de 2003.

${ }^{121}$ Documento WT/DS265/AB/R de 19 de mayo de 2005.

122 Documento WT/DS22/AB/R de 20 de marzo de 1997.
} 
ii) Estados Unidos contra Argentina por la aplicación de derechos no contemplados en las listas de concesiones a las importaciones de calzado y prendas de vestir; el fallo favoreció a Estados Unidos. ${ }^{123}$

iii) Canadá contra Brasil por los subsidios de exportación a su industria aeronáutica civil; el fallo favoreció a Canadá. ${ }^{124}$

iv) Comunidades Europeas contra Chile por los impuestos aplicados por Chile a las importaciones de bebidas alcohólicas; el fallo favoreció a las Comunidades. ${ }^{125}$

v) Comunidades Europeas contra Argentina por salvaguardias a las importaciones de calzado; el fallo favoreció a las Comunidades. ${ }^{126}$

vi) Estados Unidos contra México por la aplicación de derechos antidumping a las importaciones estadounidenses de jarabe de fructosa; el fallo favoreció a Estados Unidos. ${ }^{127}$

\section{d) Controversias entre países latinoamericanos}

Estas controversias fueron las tres siguientes:

i) México contra Guatemala por la aplicación de medidas provisionales a las importaciones mexicanas de cemento; el fallo favoreció a Guatemala. ${ }^{128}$

ii) Argentina contra Chile por el sistema de bandas de precios aplicados a las importaciones de productos agrícolas; el fallo favoreció a Argentina. ${ }^{129}$

iii) Honduras contra la República Dominicana por la aplicación dominicana de un impuesto de estampillas a la importación y venta de cigarrillos; el fallo favoreció a Honduras. ${ }^{130}$

\section{e) La demanda de Antigua y Barbuda contra Esta- dos Unidos ${ }^{131}$}

Nos referimos a esta controversia porque su tema es bastante novedoso - la aplicación del Acuerdo General sobre el Comercio de Servicios-y fue una de las últimas resueltas por el Órgano de Apelación. Se trata, además, de la demanda de un país muy pequeño en contra del más poderoso del planeta.

Antigua y Barbuda reclamó en contra de las restricciones aplicadas por Estados Unidos al suministro,

\footnotetext{
123 Documento WT/DS56/AB/R de 22 de abril de 1998.

124 Documento WT/DS46/AB/R de 20 de agosto de 1999.

125 Documento WT/DS/AB/R de 12 de enero de 2000.

126 Documento WT/DS121/AB/R de 12 de enero de 2000

127 Documento WT/DS132/AB/RW de 21 de noviembre de 2001.

128 Documento WT/DS60/AB/R de 25 de noviembre de 1998.

129 Documento WT/DS207/AB//R de 23 de octubre de 2002.

130 Documento WT/DS302/AB//R de 19 de mayo de 2005.

131 Documento WT/DS285/AB/R de 20 de abril de 2005.
}

en general, de servicios de apuestas y juegos de azar por Internet, y, en particular, de carreras de caballos. Según la demandante, en la lista de concesiones de acceso a su mercado, aprobada por Estados Unidos, ${ }^{132}$ se mencionaron "otros servicios recreacionales" y que esta referencia debía entenderse que incluía los servicios de apuestas y juegos de azar. Estados Unidos rechazó esa interpretación y señaló que jamás había sido esa su intención por cuanto existían tres leyes federales vigentes que prohibían los juegos de azar entre estados y aun dentro de ciertos estados. Sin embargo, el Panel acogió el reclamo por cuanto estimó que la mencionada lista no había prohibido de manera explícita esos servicios y, además, Estados Unidos no había logrado justificar que las leyes federales invocadas calificaran dentro de la excepción del artículo XIV a) del Acuerdo General sobre el Comercio de Servicios, esto es, que fueran "necesarias para proteger la moral o mantener el orden público". Aceptó, además, el reclamo de la parte demandante en contra de la Ley interestatal sobre carreras de caballos, por cuanto concluyó que discriminaba en contra de los proveedores de servicios de apuestas por medios electrónicos remotos.

El Órgano de Apelación revocó parcialmente la resolución del Panel. Por una parte, aceptó la defensa de Estados Unidos y la legitimidad de las restricciones establecidas por las tres leyes federales y resolvió que estaban justificadas por ser "necesarias para proteger la moral o mantener el orden público". En cambio, confirmó la resolución del Panel y el reclamo de Antigua y Barbuda de que la Ley interestatal sobre carreras de caballos discriminaba en contra de los servicios transfronterizos que entregaba por Internet. Su conclusión fue que Estados Unidos no logró demostrar que las restricciones de la ley mencionada a los proveedores extranjeros de esas apuestas se aplicaran de la misma manera a los proveedores nacionales. Esto último infringía la regla del trato nacional y el propio artículo XIV del Acuerdo General sobre el Comercio de Servicios.

\section{f) Balance}

Según la información expuesta — excluyendo las tres controversias entre países latinoamericanos- durante el período que va de mayo de 1996 a mayo del 2005, el balance es el siguiente:

- de un total de 19 controversias, los países latinoamericanos han sido demandantes individuales o

\footnotetext{
132 La lista de concesiones de acceso a su mercado fue aprobada por Estados Unidos conforme al artículo II del GATT, que constituye uno de los acuerdos conexos del Acuerdo sobre la OMC.
} 
junto con otros países en 13 casos, y demandados en 6 casos;

- de un total de 13 demandas, los países latinoamericanos han prevalecido en 11 controversias y han perdido 2;

- de un total de 6 demandas en contra de países latinoamericanos, estos últimos, con una sola excepción, las han perdido todas;

- de un total de 19 controversias en que los países latinoamericanos fueron demandantes o demandados, los países latinoamericanos prevalecieron en 12 , esto es, en dos tercios del total, y perdieron en 7 casos;
- de las 12 victorias latinoamericanas, 8 correspondieron a juicios ganados por Brasil. Por lo tanto, si se excluye a Brasil, el resto de los países tuvo 4 victorias;

- de las 7 derrotas latinoamericanas, 2 fueron de Brasil. Por lo tanto, si se excluye a Brasil, los demás países tuvieron 5 derrotas.

En las cifras anteriores se ha incluido, entre las derrotas, la demanda de Antigua y Barbuda en contra de Estados Unidos, a pesar de que en algunos aspectos fue favorable a la parte demandante, como se explicó antes.

\section{VII}

\section{La experiencia de Brasil}

\section{Resumen}

Desde 1996, Brasil ha recurrido de manera consistente y con singular éxito a la OMC para resolver sus disputas comerciales. Junto con Venezuela, fue el reclamante del primer caso planteado ante la OMC —el juicio de la gasolina - y también, junto con otros países, ha sido el reclamante de uno de los últimos casos —el juicio contra las Comunidades Europeas por las subvenciones al azúcar.

Brasil ha participado en 10 controversias ante la OMC. Ha sido demandante en 8 casos y perdido solo uno $\mathrm{y}$, de los 2 en que ha sido demandado, ha perdido uno. En total, 8 victorias y 2 derrotas.

Las dos derrotas de Brasil han sido: en su demanda contra las Comunidades Europeas por las restricciones a las importaciones de productos avícolas; y en la demanda en su contra de Canadá por las subvenciones a la industria aeronáutica que se mencionan más adelante.

Las 10 controversias en que ha participado Brasil aparecen en el cuadro 1.

\section{Descripción de las controversias en que ha participado Brasil}

A continuación hacemos una breve referencia a los principales juicios en que ha participado Brasil, por considerar que tienen relevancia y utilidad. a) Brasil y Venezuela contra Estados Unidos por sus restricciones a las importaciones de gasolina Brasil reclamó el 12 de abril de 1995, junto con Venezuela, contra la normativa aprobada por Estados Unidos para las importaciones de gasolina extranjera. En las modificaciones a la Ley de aire limpio de 1990, de este último país, se estableció que en los centros metropolitanos más contaminados debía venderse solamente gasolina limpia o "reformulada". Los reclamantes sostuvieron que la metodología utilizada por esa ley era discriminatoria y sujetaba a la gasolina importada a un trato menos favorable que el dado a la gasolina nacional. El Órgano de Apelación acogió el reclamo y resolvió que la mencionada normativa era una "discriminación injustificable" y una "restricción encubierta al comercio internacional" prohibida por el artículo XX del GATT de 1994 y ordenó a Estados Unidos modificarla y hacerla consistente con las reglas pertinentes del GATT de $1994 .{ }^{133}$

b) Filipinas contra Brasil por las medidas compensatorias aplicadas a las importaciones de coco desecado

Brasil aplicó medidas compensatorias provisionales y definitivas a las importaciones de coco desecado

\footnotetext{
${ }^{133}$ Documento WT/DS/2/R y resolución del osD del 20 de mayo de 1996.
} 
CUADRO 1

Resoluciones del Órgano de Apelación en que ha sido parte Brasil

\begin{tabular}{|c|c|c|c|}
\hline Demandante & Materia & Demandado & Resultado \\
\hline Brasil y Venezuela & $\begin{array}{l}\text { Restricciones a las importaciones de } \\
\text { gasolina }\end{array}$ & Estados Unidos & $\begin{array}{l}\text { Favorable a Brasil y } \\
\text { Venezuela }\end{array}$ \\
\hline Filipinas & $\begin{array}{l}\text { Medidas compensatorias a las importaciones } \\
\text { de coco desecado }\end{array}$ & Brasil & Favorable a Brasil \\
\hline Brasil & $\begin{array}{l}\text { Restricciones a las importaciones de productos } \\
\text { avícolas }\end{array}$ & $\begin{array}{l}\text { Comunidades } \\
\text { Europeas }\end{array}$ & $\begin{array}{l}\text { Favorable a las } \\
\text { Comunidades }\end{array}$ \\
\hline Brasil & Subvenciones a la exportación de aeronaves & Canadá & Favorable a Brasil \\
\hline Canadá & Subvenciones a la exportación de aeronaves & Brasil & Favorable a Canadá \\
\hline $\begin{array}{l}\text { Brasil, Chile, México } \\
\text { y otros países }\end{array}$ & $\begin{array}{l}\text { Enmienda Byrd (acuerdos antidumping, } \\
\text { subsidios y medidas compensatorias) }\end{array}$ & Estados Unidos & Favorable a Brasil y otros \\
\hline Brasil & $\begin{array}{l}\text { Derechos antidumping a las importaciones } \\
\text { de tubos de fundición }\end{array}$ & $\begin{array}{l}\text { Comunidades } \\
\text { Europeas }\end{array}$ & Favorable a Brasil \\
\hline $\begin{array}{l}\text { Brasil, Comunidades } \\
\text { Europeas y otros }\end{array}$ & Subvenciones a las importaciones de acero & Estados Unidos & Favorable a Brasil y otros \\
\hline Brasil & Subvenciones a la industria del algodón & Estados Unidos & Favorable a Brasil \\
\hline Brasil y otros & Subvenciones a la industria del azúcar & Estados Unidos & Favorable a Brasil \\
\hline
\end{tabular}

Fuente: Elaboración propia.

de Filipinas. Sin embargo, el Órgano de Apelación rehusó considerar el reclamo de Filipinas, por razones formales. Estimó que su justificación legal fue equivocada y no estuvo especificada en el mandato pertinente. ${ }^{134}$

\section{c) Brasil contra las Comunidades Europeas por las restricciones a las importaciones brasileñas de productos avícolas}

La resolución final de esta demanda de Brasil ante la omc le fue desfavorable.

Brasil afirmó que las Comunidades Europeas no habrían cumplido adecuadamente sus obligaciones de aplicar los aranceles y cuotas de importación de productos avícolas establecidas en un acuerdo bilateral entre ambos países y, por consiguiente, habrían infringido el artículo XXVIII del GATT, que regula las modificaciones a las listas de concesiones. Afirmó, también, que se habría infringido el artículo XIII del GATT, referente a la aplicación no discriminatoria de restric-

\footnotetext{
134 Documento WT/DS/22/AB/R y resolución del OSD de 20 de
} marzo de 1997. ciones cuantitativas, el artículo X del GATT sobre transparencia, diversas disposiciones del contrato de licencia entre ambas partes, las normas sobre trato nacional del GATT y sobre disposiciones de salvaguardia especial del artículo 5 del Acuerdo sobre la Agricultura.

El Panel, entre otras consideraciones, resolvió que Brasil no había logrado demostrar que las Comunidades Europeas hubieran faltado a sus obligaciones de administrar adecuadamente las normas sobre aranceles y cuotas de importación de productos avícolas. Apelada la resolución del Panel, el Órgano de Apelación confirmó sus conclusiones con algunas modificaciones. Ambas resoluciones fueron refrendadas por el OSD el 23 de julio de 1998. ${ }^{135}$

d) Brasil contra Canadá por subvenciones a la exportación de aeronaves civiles ${ }^{136}$

Brasil y Canadá han tenido un largo diferendo respecto de los subsidios de ambos países a sus respecti-

\footnotetext{
135 Documento WT/DS69/AB/R de 23 de julio de 1998.

136 Documento WT/DS/70 de 20 de agosto de 1999.
} 
vas industrias aeronáuticas civiles, el que con posterioridad se ha resuelto por mutuo acuerdo de las partes.

Se trata de dos controversias principales y dos controversias subsidiarias surgidas, estas últimas, al no producirse acuerdo respecto del cumplimiento de los fallos respectivos del Órgano de Apelación.

A continuación describimos la demanda interpuesta por Brasil, cuyo fallo favoreció a este país.

Brasil reclamó contra las subvenciones de Canadá y algunas de sus provincias a su industria aeronáutica, debido a que estarían prohibidas por los artículos 3.1 a) y 3.2 del Acuerdo SMC. El panel resolvió el 14 de abril de 1999 que dos de las medidas reclamadas constituían "subvenciones supeditadas de facto a los resultados de exportación" y, por lo tanto, prohibidas por los artículos mencionados.

El Órgano de Apelación acogió el reclamo de Brasil y ordenó la eliminación de las medidas cuestionadas. Sin embargo, no hubo acuerdo respecto del cumplimiento del fallo, por lo cual Brasil solicitó autorización para suspender concesiones y otras obligaciones mediante contramedidas conforme a los artículos 22.2 del Entendimiento, 4.10 del Acuerdo SMC y VI(6)(a) del GATT por el equivalente a 3.360 millones de dólares. Esta petición fue rechazada por Canadá y el asunto fue sometido a arbitraje conforme al artículo 22.6 del Entendimiento. La resolución arbitral aprobó la suspensión de concesiones y la adopción de "contramedidas apropiadas" pero resolvió que, conforme al artículo 4.10 del Acuerdo SMc, la suma apropiada era de 247.797.000 dólares, monto por el cual Brasil fue autorizado a efectuar suspensiones. Sin perjuicio de esto último, el árbitro señaló que, conforme al artículo 22.8 del Entendimiento, la suspensión de concesiones u otras obligaciones sería temporal y solo se aplicaría hasta que se hubiera suprimido la medida prohibida. Agregó, también, que sabía que las partes realizaban consultas para llegar a una solución mutuamente satisfactoria y que, dadas las circunstancias del caso y en un contexto más amplio, esa parecía ser la solución más apropiada. ${ }^{137}$

e) Canadá contra Brasil por subvenciones a la exportación de aeronaves civiles $^{138}$

Esta demanda de Canadá fue contra el financiamiento subsidiado de Brasil al Programa de incentivos a las exportaciones (PROEX), que fomentaba la expor-

\footnotetext{
137 Véanse los artículos VIII y III del Acuerdo sobre la OMC.

138 Documento WT/DS46/AB/R de 20 de agosto de 1999.
}

tación de aeronaves civiles, y el panel correspondiente fue establecido el 23 de julio de 1998.

El Órgano de Apelación acogió el reclamo de que los intereses pagados bajo el PROEX constituían una subvención conforme al artículo $1^{\circ}$ del Acuerdo sMC. Resolvió que Brasil no había cumplido con sus obligaciones, bajo el artículo 27.4 de dicho Acuerdo, de no aumentar "el nivel de sus subvenciones a la exportación". Además, por ser subvenciones "supeditadas a los resultados de exportación" le eran aplicables las prohibiciones del artículo 3.1a) del mismo Acuerdo. Enseguida, confirmó la conclusión del panel de que Brasil no había demostrado que las subvenciones a PROEX no hubieran sido utilizadas "para lograr una ventaja importante en las condiciones de los créditos a la exportación". ${ }^{139}$ En base a estas consideraciones se resolvió que Brasil debía retirar las subvenciones a la exportación de sus aeronaves bajo el PROEX, lo que fue confirmado por el osD el 20 de agosto de 1999.

$\mathrm{Al}$ no haber acuerdo respecto del cumplimiento del fallo por parte de Brasil, Canadá solicitó la formación de un panel conforme al artículo 21.5 del Entendimiento, el cual se estableció el 9 de diciembre de 1999. En su informe, el Panel concluyó que Brasil no había puesto su PROEX en conformidad con el Acuerdo SMC. Brasil apeló y, además, solicitó arbitraje ${ }^{140}$ para que se determinara la justificación de las contramedidas solicitadas por Canadá. El Órgano de Apelación confirmó la resolución del Panel de que Brasil no había puesto en conformidad el PROEX con el Acuerdo SMC, lo que fue aprobado por el osD el 4 de agosto de 2000.

Por otra parte, los árbitros resolvieron que Canadá podía justificar contramedidas hasta por 344 millones de dólares canadienses por año durante seis años y suspender concesiones por ese monto. Esto fue aprobado por el OSD el 12 de diciembre de 2000. En esa misma fecha, Brasil informó al OSD de los cambios efectuados en el PROEX y de la conformidad de este último con el Acuerdo SMC. Sin embargo, Canadá no estuvo de acuerdo y solicitó, por segunda vez, la formación de un panel en virtud del artículo 21.5 del Entendimiento. El Panel, esta vez, concluyó que las revisiones efectuadas por Brasil al PROEX III no eran inconsistentes con el Acuerdo SMC, lo que fue aprobado por el OSD el 23 de agosto de 2001.

\footnotetext{
139 Véase el Anexo I del Acuerdo smc.

${ }^{140}$ Respecto del concepto de arbitraje, véase más atrás la sección III, apartado 7.
} 
f) Brasil, Chile, México, las Comunidades Europeas y otros países contra Estados Unidos por la Enmienda Byrd ${ }^{141}$

La legislación estadounidense del 2000 conocida como Enmienda Byrd, modificó una Ley de aranceles de 1930 y permitió que los derechos de importación recaudados por el Tesoro bajo la legislación antidumping y sobre derechos compensatorios fueran transferidos a las empresas que hubieran denunciado infracciones a la mencionada legislación.

El Órgano de Apelación resolvió que la Enmienda mencionada sería una medida específica contra el dumping o las subvenciones no permitida y contraria a los Acuerdos ADP y SMC. Resolvió que Estados Unidos habría infringido esos Acuerdos y el artículo XVI(4) del Acuerdo sobre la omc que obliga a los países miembros a asegurar la conformidad de sus leyes, reglamentos y procedimientos administrativos con las obligaciones que les imponen los acuerdos multilaterales conexos. Al incurrir en estas infracciones, Estados Unidos habría anulado o menoscabado los beneficios conferidos a los reclamantes por esos acuerdos.

$\mathrm{Al}$ discrepar las partes respecto de las medidas adoptadas por Estados Unidos para dar cumplimiento al fallo, Brasil solicitó suspender concesiones arancelarias y obligaciones conexas al GATT de 1994, lo que fue sometido a una decisión arbitral. La resolución adoptada estableció que Brasil podía suspender concesiones mediante la imposición de derechos de importación adicionales a una lista definitiva de productos originarios de Estados Unidos. Esta lista abarcaría, anualmente, un valor total de comercio no superior al importe de una determinada ecuación. Esta consideraría la cuantía de los desembolsos bajo la Enmienda Byrd durante el último año del cual se dispusiera de datos sobre los derechos antidumping o compensatorios pagados por Brasil en ese año, multiplicado por un coeficiente que debería asegurar que el nivel de suspensión sería equivalente al de la anulación o menoscabo de los beneficios que los acuerdos infringidos confirieron a Brasil. ${ }^{142}$ Estados Unidos informó que el 3 de marzo de 2005 fue presentada a la Cámara de Representantes una ley que derogaría la Enmienda Byrd. ${ }^{143}$

\footnotetext{
${ }^{141}$ Brasil fue uno de varios reclamantes. Esta referencia es solo al reclamo de Brasil.

${ }_{142}$ Documento WT/DS217/ABB/BR de 31 de agosto de 2004.

143 Información sobre el osD de 21 de marzo de 2005, contenida en OMC (2005).
}

g) Brasil contra las Comunidades Europeas por derechos antidumping a las importaciones brasileñas de tubos de fundición maleable

Brasil reclamó contra las Comunidades Europeas por haber infringido el Acuerdo ADP en su aplicación de derechos antidumping a las mencionadas importaciones. Chile participó como tercero interesado y formuló observaciones al fallo.

El Órgano de Apelación resolvió que las Comunidades habrían infringido los artículos 6.2 y 6.4 del Acuerdo ADP al no entregar a los exportadores brasileños, durante el proceso de investigación de la denuncia de dumping, la información disponible acerca de los factores enumerados en el artículo 3.4 de ese Acuerdo, que afectarían la producción nacional respectiva. Como estos factores e indicadores económicos influían en el estado de la rama de la producción nacional afectada por el dumping, los exportadores brasileños no habrían tenido acceso a una adecuada defensa durante esa investigación. El Órgano de Apelación falló a favor de Brasil por estimar que la entrega oportuna de tal información por parte de las Comunidades Europeas era un componente esencial del proceso y que su omisión no podía sanearse retroactivamente.

h) Brasil, las Comunidades Europeas y otros países contra Estados Unidos por las salvaguardias a las importaciones de acero

Las Comunidades Europeas, Brasil y otros países reclamaron en contra de las salvaguardias aplicadas por Estados Unidos a las importaciones de acero por estimar que habrían infringido los artículos XIX 1) a) del GATT de 1994 y 3.1 del Acuerdo SVG. La petición se basó en que Estados Unidos no habría entregado una explicación adecuada y razonada de las "circunstancias imprevistas" que habrían provocado un aumento de las importaciones en cantidad tal que habría causado un daño grave a los productores nacionales pertinentes.

El Órgano de Apelación acogió los reclamos y agregó que la aplicación de salvaguardias a ciertos productos de acero era inconsistente con los requisitos de los artículos 2.1 y 3.1 del Acuerdo svG, por cuanto Estados Unidos no fundamentó los hechos que apoyaron su determinación respecto del aumento de las importaciones. También, estimó que era inconsistente con los artículos 2.1 y 4.2 del Acuerdo sVG, por cuanto Estados Unidos no cumplió con el requisito de "paralelismo" entre los productos respecto de los cuales las salvaguardias fueron establecidas y los productos a los cuales 
fueron aplicadas las medidas. ${ }^{144}$ El Órgano de Apelación recomendó, y el osD acordó que las medidas cuestionadas fueran puestas en conformidad con las disposiciones del Acuerdo svg y el 4 de diciembre de 2003 la Casa Blanca anunció el término de estas medidas. ${ }^{145}$

\section{i) Brasil contra Estados Unidos por sus subvencio- nes a la industria del algodón}

El reclamo de Brasil contra los subvenciones de Estados Unidos a su industria del algodón fue acogido por el Órgano de Apelación y aprobado por el OSD el 21 de marzo de 2005. Se resolvió que los pagos y apoyo de Estados Unidos a esta industria, estimados en más de 3.000 millones de dólares anuales, infringieron el Acuerdo sobre la Agricultura, el Acuerdo SMC y el GatT de 1994. Constituyeron una "ayuda a un producto básico específico" prohibido por el Acuerdo sobre la Agricultura, y los efectuados durante los años 1999, 2000, 2001 y 2002 excedieron los otorgados en 1992 y quedaron afectos a las acciones de los artículos 5 y 6 del Smc y XVI (1) del gatT de 1994. Además, subvaloraron los precios internos y perjudicaron así al producto importado con infracción del artículo 6(2) ii), y fueron subvenciones prohibidas por los artículos 3.1(b) y 3.2 del Acuerdo SMC, respectivamente. Los créditos y garantías fueron calificados como subvenciones supeditadas a la exportación y, por lo tanto, igualmente prohibidas por el Acuerdo SMC. Se concluyó que las mencionadas medidas no eran compatibles con el Acuerdo sobre la Agricultura y el Acuerdo smC y que debían ser puestas en conformidad con las disposiciones de estos últimos acuerdos.

\section{j) Brasil, Australia y Tailandia contra las Comuni- dades Europeas, por sus subvenciones a la indus- tria del azúcar (2005)}

Una particularidad de esta controversia fue que, además de las partes directamente involucradas, parti- ciparon como terceros interesados un total de 22 países, entre ellos China, Canadá, Estados Unidos, India, y también países productores de azúcar de África, el Caribe y el Pacífico. Estos últimos, llamados "países ACP", reciben apoyo financiero de las Comunidades Europeas.

Los reclamantes afirmaron que los subsidios otorgados por las Comunidades Europeas a la industria del azúcar eran superiores a los límites especificados en sus respectivas listas de concesiones, lo cual infringía el Acuerdo sobre la Agricultura y el Acuerdo smc. De manera especial, los reclamantes sostuvieron que las Comunidades Europeas garantizaban un alto precio al azúcar incluido dentro de las respectivas cuotas de producción, pero que el azúcar que excedía esas cuotas, llamada azúcar C, no podía ser vendida internamente sino que debía ser exportada. Los altos precios pagados a los productores y procesadores permitían financiar la producción y exportación del azúcar C a precios inferiores a sus costos de producción. Además, se afirmó que las Comunidades otorgaban subsidios de exportación a aproximadamente 1,6 millones de toneladas, cuyo valor sería equivalente al de las importaciones recibidas de los países ACP. Al exceder los valores y volúmenes de estas exportaciones los límites comprometidos y acordados, los subsidios de las Comunidades Europeas habrían infringido las disposiciones pertinentes del Acuerdo sobre la Agricultura y del Acuerdo SMC. ${ }^{146}$

La resolución del Panel acogió los reclamos de los demandantes y fue confirmada por el Órgano de Apelación. Se resolvió que las infracciones de las Comunidades Europeas anulaban o menoscababan los beneficios que el Acuerdo sobre la Agricultura conferían a los demandantes y se recomendó a las Comunidades enmendar su reglamentación sobre el azúcar y conformarla a las disposiciones del mencionado Acuerdo.

\footnotetext{
144 Documento WTS251/AB/R y resolución del osD de 10 de diciembre de 2003.

145 www.whitehouse.gov.newsrelease.
}

146 Artículo 3.3, artículo 8 y artículo 9.1 a) y c) o, en la alternativa, artículo 10.1 del Acuerdo sobre la Agricultura, y artículo I, acápite 1.1, incisos a)1) i) y a)1) iv), e incisos a)2) b) del Acuerdo SMC. 


\section{VIII}

\section{Conclusiones}

Sin perjuicio de que los gobiernos deben siempre priorizar la vía diplomática para resolver sus conflictos comerciales con otros países, ${ }^{147}$ el procedimiento de la OMC presenta la ventaja de que, a través de la consulta, pueden lograrse soluciones bastante similares. La información analizada muestra que cuando la consulta fracasa y las controversias son entregadas a la decisión de un panel, en general los resultados han favorecido a los países latinoamericanos. Esto debe atribuirse al hecho de que el procedimiento es predecible y es administrado por tribunales independientes que aplican e interpretan de manera objetiva reglas acordadas multilateralmente.

Dado que las controversias son exclusivamente entre Estados, pero interesan y afectan a intereses privados, es fundamental que los gobiernos mantengan una estrecha coordinación con los exportadores e importadores nacionales. Esta coordinación debería ser constante y no surgir solamente ante una determinada controversia. Su objetivo debe ser la prevención, de manera de anticipar los problemas y así poder adoptar las medidas o conductas que sean pertinentes. Por lo general son los ministerios de relaciones exteriores o de comercio, o ambos, los que representan los intereses de los Estados en estas materias frente a la omc. Sin perjuicio de ello, la complejidad y naturaleza técnica de estos asuntos exigen que, para su debida atención, los gobiernos dispongan del apoyo de profesionales especializados, particularmente en el área legal. Una opción que muchos países - particularmente los más débiles- deberían considerar antes de iniciar o responder un reclamo es la de solicitar la asesoría del ya mencionado Centro de Asesoría Legal en Asuntos de la omc, de Ginebra, cuyos costos son inmensamente inferiores a los de cualquier bufete internacional.

La jurisprudencia reiterada de los últimos diez años permite, en determinadas materias, anticipar los resultados de una controversia y obliga a los países a examinarla cuidadosamente antes de presentar un reclamo. Sin embargo, factores de política interna generan a veces reacciones precipitadas, destinadas solamente a satisfacer la opinión pública local, o presiones a veces inconsultas del sector privado perjudicado. Estas reacciones, además de resultar generalmente infructuosas, terminan invariablemente por afectar la credibilidad de los gobiernos y deben ser siempre resistidas.

Hay dos opciones que los gobiernos latinoamericanos deberían considerar.

La primera es participar con alguna frecuencia como terceros interesados en aquellas controversias que comprometan sus intereses, aunque sea indirectamente. Esta participación no reviste mayores costos y permite a los gobiernos familiarizarse con los procedimientos y funcionamiento del sistema y adquirir así la experiencia necesaria para enfrentar con éxito futuras controversias ante la OMC.

La otra opción es que los gobiernos consideren asociarse con otros países - particularmente de la OCDE - en controversias de gran magnitud. Las veces que lo han hecho, los resultados han sido generalmente favorables. Casos ilustrativos han sido los reclamos: de Ecuador junto con Estados Unidos y otros países contra las Comunidades Europeas por las restricciones a las importaciones de bananos; de Brasil junto con las Comunidades Europeas y con otros países contra Estados Unidos por los aranceles impuestos a las importaciones de acero; y de Brasil, Chile, México y las Comunidades Europeas contra la Enmienda Byrd. Los resultados de todos estos reclamos han favorecido siempre a los reclamantes y, posiblemente, esto no habría ocurrido si los países latinoamericanos hubieran actuado de manera aislada. ${ }^{147}$ Un buen ejemplo de la utilización exitosa de la vía diplomática
para resolver o prevenir controversias fue la gestión realizada por
Chile para impedir la aplicación por las Comunidades Europeas de salvaguardias a las importaciones de salmón. 
Bibliografía

Barfield, C. (2004): Testimonio respecto de la OMC ante el Comité de Pequeños Negocios de la Cámara de Representantes de Estados Unidos, 7 de julio.

Barrionuevo, A. y E. Becker (2005): Fewer friends in high places for this lobby, The New York Times, Nueva York, 2 de junio.

Cámara de Representantes de los Estados Unidos (2003): Opinión expresando rechazo del fallo del Órgano de Apelación de la OMC sobre el juicio del acero, Resolución $\mathrm{N}^{\mathrm{N}} 445$ de 18 de noviembre de 2003.

CEPAL (Comisión Económica para América Latina y el Caribe) (1994): Balance preliminar de la economía de América Latina y el Caribe, 1994, LC/G.1846, Santiago de Chile.

(2004): Balance preliminar de las economías de América Latina y el Caribe, 2004, LC/G.2265-P, Santiago de Chile, diciembre. Publicación de las Naciones Unidas, $\mathrm{N}^{\circ}$ de venta: S.04.11.G.147.

CIADI (Centro Internacional de Arreglo de Diferencias Relativas a Inversiones) (2004): Informe anual, 2004, Washington, D.C.

Columbia Electronic Enciclopedia (2003): La ley Smoot- Hawley, sexta edición.

GAO (Oficina General de Contabilidad de los Estados Unidos) (2000): World Trade Organization. U.S. Experience in Dispute Settlement System: the First Five Years, Washington, D.C., 20 de junio.

(2003): World Trade Organization. Standard of Review and Impact of Trade Remedy Rulings, Washington, D.C., 30 de julio.

GATT (Acuerdo General sobre Aranceles Aduaneros y Comercio (1994): Los resultados de la Ronda Uruguay de negociaciones comerciales multilaterales. Los textos jurídicos, Ginebra, Secretaría del GATT, diciembre.

Horlick, G.N. (1998): The consultation phase of wTO dispute resolution: a private practitioner's view, The International Lawyer, vol. 32, $\mathrm{N}^{\mathrm{o}} 3$, Chicago, Illinois, American Bar Association.

Husted, S.L. (1995): Western Hemisphere free trade and United States trade laws: the role of section 301, Trade Liberalization in the Western Hemisphere, Washington, D.C., Banco Interamericano de Desarrollo (BID)/Comisión Económica para América Latina y el Caribe (CEPAL).

Jackson, J.H. (1999): The World Trade Organization. Constitution and Jurisprudence, Londres, The Royal Institute of International Affairs.
Jung, Y. y E. Jooyeon Kang (2004): Towards an ideal safeguards regime, The International Lawyer, vol. 38, $\mathrm{N}^{\circ} 4$, Chicago, Illinois, American Bar Association.

OCDE (Organización de Cooperación y Desarrollo Económicos) (2004): Agricultural Policies, 2004, París, disponible en www.oecd.org.

OMC (Organización Mundial del Comercio) (1995): Analytical Index. Guide to GATT Law and Practice, Ginebra. (2004a): Informe anual, 2004, Ginebra.

(2004b): A Handbook on the WTO Dispute Settlement System, Cambridge, Cambridge, Cambridge University Press. (2005): Noticias 2005, Ginebra, 21 de marzo.

Informes de los grupos especiales y del Órgano de Apelación, disponibles en http:///spanish/tratop_s/distabase_s.htm.

Petersmann, E. (1997): International trade law and the GATT/WTO Dispute Settlement System 1948-1996: an introduction, Studies in Transnational Economic Law, vol. 11, La Haya, Kluwer Law International.

Ragosta, J., N. Joneja y M. Zeldovich (2003): WTO dispute settlement: the system is flawed and must be fixed, The International Lawyer, vol. 37, $\mathrm{N}^{\mathrm{o}} 3$, Chicago, Illinois, American Bar Association.

Senado de los Estados Unidos (2003): Resolución N ${ }^{\circ} 676$ de 20 de marzo de 2003, que establece una Comisión de revisión de los fallos o informes del Órgano de Apelación y demás órganos de la OMC, Washington, D.C.

Senado de los Estados Unidos/Cámara de Representantes de los Estados Unidos (2003): Resolución concurrente sobre la OMC, $\mathrm{N}^{\mathrm{o}} 243$, Washington, D.C., de 15 de julio de 2003.

Shaffer, G. (2005): Weaknesses and Proposed Improvements of the WTO Dispute Settlement System: An Economic and Market oriented View, Reunión regional del Órgano de Apelación de la OMC (São Paulo 16 y 17 de mayo de 2005).

Smith, J. (2004): Inequality in international trade? Developing countries and institutional change in WTO dispute settlement, Review of International Political Economy, vol. 11, No 3 Londres, Routledge.

Steger, D. (2005): The WTO in Public International Law: Jurisdiction, Interpretation and Accommodation, Reunión regional del Órgano de Apelación de la OMC (São Paulo 16 y 17 de mayo de 2005).

Tegel, S. (2004): The wTO cotton case, Berkeley Review of Latin American Studies, Berkeley, University of California. 